\title{
INTRODUCTION TO THE ISSUE
}

This issue of the Journal of Vocational Rehabilitation examines community integration. Drawing from a variety of experiences in differing settings, the authors of the following articles explore this subject. Allow me to introduce them.

The article written by Jim Prentice, "Community Factors Can Make a Difference," is a firstperson account of an interesting odyssey. Jim fits a profile of thousands of people with disabilities who have not been able to make it in the work world. He uses a chair, and with one thumb controls his voice-coded communicator. By all rights he should be sitting in some therapeutic activity center. Yet, Jim is a full-time programmer for Westinghouse Electric Company in Monroeville, Pennsylvania. What has set Jim apart, as he relates in his article, are his perseverance and the persistent family and community factors present in his life.

The next article, "Vocational Rehabilitation of Persons with Disabilities: Family Inclusion," by Kenny Hosack and Danese Malkmus, explores a more focused approach of family as a key community factor. The authors are associated with the Learning Services Corporation, a national support system with a special interest in traumatic head injury. Their work outlines ways and means for rehabilitationists to actively incorporate families into the process.

Next is a review of how one type of vocational rehabilitation effort, supported employment, can and does combine the philosophy and spirit essential to the incorporation of community factors. "Beyond Vocational Services: Looking to Community," by Mary Ridgely, uses actual experiences to make its point. The author's experience with Employment Resources, Inc., of Madison, Wisconsin, offers a unique lens through which to understand community factors.

Also building on individual experiences is "Home-Based Support: The Link to Employability," by Sally Kneipp. Using an in-home methodology to incorporate community factors, the author's firm, Rehabilitation and Counseling Associates, which reaches eastern Pennsylvania and New Jersey, has made unique progress with people who the system has failed.

Lori Ferris, Melva Gooden, and Susan Linders explore how community factors affect a holistic approach to rehabilitation in their article, "Adult Living, Working, and Playing: A Holistic Support Style." In their work with the Centre for Personal Development, a program of United Cerebral Palsy of Pittsburgh, community factors play a vital role in the overall success that people have achieved.

In the next article, "Enhancing Interdependent Relationships between Counselors and Consumers: A Conceptual Model," Richard Murray examines various relationship styles and how the human service shift to interdependence is vital to vocational success. A rehabilitation psychologist, the author has had a variety of experiences on which to base his judgments.

The final article focuses on research from the field. In "Strategies for Increasing Interactions in Supported Employment Settings," Keith Storey and Linda Lengyel review data-based research designed to increase the social interactions of workers with severe disabilities in supported employment settings. The authors are with the Alleghney-Singer Research Institute in Pittsburgh.

Through these articles, the impact of community factors becomes vivid. They offer rationale, strategies, insight, and inspiration. The authors represent consumers, advocates, practitioners, and researchers; it is hoped this rounded exploration will be a benefit to all.

There is so much more for us to do. The continued failure of rehabilitation to place and maintain people with severe disabilities in the job market demands that we leave no stone unturned. The use of community factors offers some new options. Like task analysis, adaptive technology, and supported employment before, it may not offer all the solutions to this problem, but if the use of community factors allows one more person with a disability to be a part of the work force, then the efforts of these authors will have been worthwhile.

Al Condeluci, PhD 